NBER WORKING PAPER SERIES

LIABILITY FOR HARM VERSUS

REGULATION OF SAFETY

Steven Shavell

Working Paper No. 1218

NATIONAL BUREAU OF ECONOMIC RESEARCH

1050 Massachusetts Avenue

Cambridge, MA 02138

October 1983

The research reported here is part of the NBER's research program in Law and Economics. Any opinions expressed are those of the author and not those of the National Bureau of Economic Research. 
Liability For Harm Versus Regulation of Safety ABSTRACT

Liability in tort and the regulation of safety are considered as means of controlling accident risks using the instrumentalist, economic method of analysis. Four general determinants of the relative social desirability of liability and regulation are first identified -differences in knowledge about risky activities as between a social authority and private parties; the possibility that parties would not be able to pay fully for harm done; the chance that they would not face suit for harm done; and administrative costs. On the basis of analysis of these determinants, it is suggested that the choices observed to be made between liability and regulation are, when broadly viewed, socially rational: Notably, activities that create the risk of the typical tort and that are little regulated characteristically display features leading us to say that they ought to be controlled mainly by liability. And activities that are much regulated -- especially ones involving significant hazards to health or to the environment -- ought to be directly constrained in important ways, taking into account their usual features.

[forthcoming in Journal of Legal Studies] 


\section{Liability for Harm versus Regulation of Safety}

\section{S. Shavell*}

\section{Introduction}

Liability in tort and regulation of safety represent two very different approaches for controlling activities that create risks of harm. ${ }^{1}$ The approach of liability is private in nature and works in a manner that is in essence indirect, for behavior under it is not determined by command of a social authority but rather by the deterrent of payment of money damages should harm occur. Standards, prohibitions, and other forms of safety regulation, in contrast, are public in character and operate in principle in an immediate way to alter behavior; they are requirements imposed on behavior ex ante--before, or at least independent of, the actual occurrence of harm. ${ }^{1 a}$

It is apparent that these two means of controlling risks are employed with an emphasis that varies considerably according to the activity. Whether I run to catch a bus and perhaps collide with someone in the process will be influenced more by the possibility of my liability than by any prior regulation of my behavior; ${ }^{2}$ and similarly, for example, with how I choose to fell a tree in my backyard when there is a chance that it would strike the roof of my neighbor's garage. But whether I drive my truck through a tunnel when 
carrying a load of explosives, whether I mark exits to be used in case of fire in my store, whether an electric utility incorporates certain safety features into the design of a nuclear power plant--such decisions will often be determined substantially by regulation.

What leads society sometimes to rely primarily on liability to reduce risks and other times on regulation? When is it socially desirable to employ one means of control and when the other? These are the questions to be addressed here. In considering them, the instrumentalist, economic method of analysis will be used. That is, the effects on behavior of liability and of regulation will be compared and then evaluated on a utilitarian basis, given that parties can be expected to act in their self-interest. 2 a

The plan of the article will first be to identify four general determinants of the relative social desirability of liability and of regulation. Then it will be suggested that in light of these determinants, the choices observed to be made between the two approaches for controlling risk are, when very broadly viewed, socially rational: Notably, activities that create the risk of the typical tort (the tree falling on my neighbor's garage) and that are little regulated characteristically display features which would lead us to say that they ought to be controlled mainly by liability. And activities that are much regulated -- especially ones involving significant hazards to health or to the environment -- ought to be directly constrained in important 
ways, taking into account their usual features. Following this, several qualifying remarks will be made in a brief concluding section and the possibility of extending the analysis to a broader consideration of the control risk that would include the use of fines and injunctions will be noted. 
I . Theoretical Determinants of the Desirability of Liability and of Regulation of Safety

In discussing the factors that will be claimed to predispose society toward reliance on liability or on regulation to control risk, it will be convenient to consider a measure of social welfare depending on the value of engaging in risky activities, the difficulties and expense involved in reducing risks, the harms that occur, and the administrative costs associated with the use of liability and of regulation. ${ }^{3}$ These variables, then, will be seen as deciding whether and at what level it would be socially desirable that parties engage in risky activities, the steps that should be taken to reduce risks, and the best use of liability and of regulation. With this in mind the determinants will now be examined.

The four determinants. The determinant of initial concern is the possibility of a difference in knowledge about risky activities possessed by private parties and by a regulatory authority. The difference in knowledge might be over the value of parties' activities, the costs of reducing risks, or the probability or magnitude of risks.

If the private parties possess information about these elements that is superior to the regulatory authority's, then, other things equal, it would be desirable for it to be the parties who perform the calculations to decide how to control risks. Thus there would appear to be an advantage 
in the use of liability. Conversely, if the authority possesses the better information, the social advantage would seem to lie in the direction of use of regulation.

To be more precise about the nature of this argument, consider the situation where private parties possess perfect information about a risky activity and the regulatory authority has only imperfect knowledge about it. Then under regulation, if the authority would overestimate the potential for harm, it would set too stringent a standard, and likewise if it would underestimate the value of the activity or the cost of reducing risk. On the other hand, if the regulatory authority would make the reverse errors, it would announce a standard that is lax.

Under the approach of liability, however, the outcome would likely be better. That this would be so is readily seen if liability were strict--if parties had to pay for losses caused regardless of their fault--for then they would be motivated to balance the true costs of reducing risk against the true benefits in terms of expected savings in losses caused. Now assume that the form of liability is the negligence rule--under which parties are held responsible for harm only if their level of care falls short of a level of "due" care--and suppose that the courts would acquire enough information if harm were done from learning about the nature of the incident in question to be able to formulate the appropriate level of due care. Then the parties, anticipating this, would in principle be led to exercise that 
level of care. ${ }^{4}$ The situation is altered of course if the courts are not assumed to be able to acquire sufficient information to determine an appropriate standard of due care; but the situation would still be superior to that under regulation if the information which the courts would normally obtain in the event of harm would be better than that which a regulatory authority would be capable of bringing to bear ex ante.

(In the case where it is the regulatory authority that possesses the superior information, an argument can obviously be given in favor of regulation analogous to the one in favor of liability that was just discussed.)

Having identified how a difference in knowledge about risk affects the relative desirability of liability and of regulation, the question must be asked what differences in knowledge would actually be expected to exist. As a general matter, the answer would seem to be that private parties should enjoy an inherent advantage in knowledge in virtue of their position. They, after all, are the ones who are engaging in and deriving benefits from their activities; as a kind of byproduct of this, they should know quite a lot about the nature of the risks created, the costs of reducing the risks, and changes in the risks or in the costs of reducing them. 5 similarly, it would seem that the courts ought usually to have an advantage in knowledge over a regulatory authority; one would expect the courts to be better able to adjust the due care standard on the basis of particular sets of facts adduced by private parties who have 
caused harm than a regulatory authority would be able to individualize its prior standards of behavior. ${ }^{6}$

Yet this is not to say that private parties (or the courts) would necessarily possess information superior to that of a regulatory authority, for in certain contexts information of significance about risk or its reduction is not an obvious byproduct of engaging in risky activity but rather requires effort to develop or special expertise to evaluate. Where this is so, the regulatory authority might possess the superior information ${ }^{7}$ and, further, be unable to communicate it easily to private parties because for instance of its technical aspect. Thus, a case can be made for why the regulatory authority might possess better information than private parties' and not transmit it to them, even if the usual expectation would be for the parties to possess the superior information.

The second determinant of interest is that private parties might be incapable of paying for the full magnitude of harm done. To the extent that this is so, potential liability would not furnish an adequate incentive to reduce risk. Specifically, such would be the case because liability exceeding a party's assets would be seen by him only as liability equal to his assets; thus the party's motive to reduce risk would be less than society's. ${ }^{8}$

But under the regulatory approach possible incapacity to pay for harm done would be a matter of irrelevance, for 
parties would be made to take steps to reduce risk as a precondition for engaging in their activities. 9

of course, in assessing the importance of this argument in favor of regulation over liability, a variety of considerations needs to be taken into account: most obviously, the size of parties' assets in relation to the chances of various magnitudes of harm; in addition, the voluntary or required purchase of liability insurance and its effects on behavior; and further, the type of private party--whether a large enterprise as opposed to an individual or to a severalperson firm. The latter considerations bear comment.

Regarding liability insurance, it should first be observed that a party's motive to purchase coverage against having to pay damages substantially exceeding his assets will be a diminished one. This is because the purchase of such coverage is in effect the purchase of protection against losses which the party would otherwise have to bear only in small part. ${ }^{10}$ Thus the party may well decide against the purchase of coverage much exceeding his assets, meaning that the argument under consideration in favor of regulation would be essentially unaffected.

If, however, the party does decide to purchase coverage against liability significantly exceeding his assets or is required by statute to do so, the question that needs to be asked is what his incentive to take care would then be. And the answer depends on whether insurers can easily determine risk-reducing behavior and link the premium charged (or the conditions of coverage) to such behavior. If this can be 
done, then the motive of insureds to take care should be tolerably good; but if insurers find it difficult to verify efforts at risk-reduction and do not do so, then the motive of insureds to take care may be insufficient, and plausibly lower than if they did not own coverage. ${ }^{11}$ Accordingly, the problem of the inadequacy of the incentive to reduce risk that would exist were parties uninsured and unable to pay fully for harm done may either be mitigated or exacerbated by their purchase of liability insurance.

With respect now to the other consideration, concerning the type of private party, what is of special interest is the situation where the party is a large firm; for the activities of a large firm are prone to result in large liabilities, and although the firm may have assets sufficient to cover them, individuals within the firm often will not. In consequence, the firm's ability to induce its decisionmakers to reduce the risk of corporate liability by the threat of recovery from them or by imposition of penalties of its own devise may be limited, and this in turn may increase the appeal of regulation. 12

The third general determinant of the relative desirability of liability and of regulation is that parties might not face the threat of suit for harm done. Such a possibility clearly means that liability might not result in proper incentives to reduce risk, whereas it would be of no import under regulation. 
The relevance of this determinant favoring regulation depends on the presence of causes of failure to bring suit. One of these causes is the chance of dispersal of harm over many victims, making it less than worthwhile for any particular victim to initiate legal action. (However, in certain contexts the victims' opportunity to employ the device of the class action limits the importance of this as a problem for liability.) A second cause of failure to bring suit is the passage of a long period of time before harm eventuates. This raises the possibility that by the time suit could be brought, the evidence necessary for a successful action would be stale or that the responsible parties would be defunct. And a third source of victims' failure to bring suit is difficulty in attributing harm to responsible parties. This problem may arise for reasons ranging from simple ignorance that a harm could have been caused by another party (as opposed to being "natural" in origin), to inability to make other than rough guesses about the role played by numerous other parties of varying description, to the impossibility of saying which among a fairly well-defined group of parties caused the loss. ${ }^{13}$

In addition, a point about large firms analogous to the one made two paragraphs above should be mentioned. Namely, even if harms can be linked to the actions of firms and suits successfully brought, the effect of the prospect of suit on the behavior of decisionmakers within firms may be slight; with the passage of time, for example, there might be no 
clear way of identifying which among the employees of the firm were the responsible parties; and the responsible parties might no longer be working at their firms. In other words, the problem that decisionmakers might not face the threat of suit or some other penalty for harm done may still exist at one remove.

The last general determinant of interest is the magnitude of the various administrative costs incurred by private parties and by the public in connection with use of the legal system and with regulation. 14

In this regard, it is tentatively suggested that there is an underlying advantage in favor of liability, for under liability administrative costs are borne only if harm occurs. Thus, if harm is unlikely, administrative costs will be low. If the possibility of some harm is eliminated because of the deterrent effect of liability, then no administrative costs will be borne; in effect, the reduction of that risk of harm will have been accomplished for free. Under regulation, on the other hand, administrative costs are incurred whether or not harm occurs; even if the risk of a harm is eliminated by regulation, administrative costs will have been borne in the process.

In evaluating the importance of this point, one factor that needs to be taken into account is that a systematic difference may exist between the administrative costs borne per instance of enforcement of regulation and per instance 
of use of the liability system. This factor may work either to reinforce or to diminish or offset the initial advantage of liability. A second factor of relevance, and one which tends to enhance the advantage of liability, is that even when an accident occurs, often there will not be a suit or litigation. $14 a$

A third factor, but working in favor of regulation, is that determining adherence to regulatory requirements need not involve verification with certainty; administrative costs may be lowered by use of probabilistic methods of enforcement. ${ }^{14 b}$ There is, however, a bound to the savings that can be achieved by this strategy, at least because there is a minimum frequency of verification that must be maintained to induce parties' adherence to a regulation. 15 And a fourth factor of relevance is the desirability that administrative costs be "focused" on controlling the group of parties most likely to cause harm. This occurs naturally under liability just because administrative costs are incurred only for parties who actually cause harm. (The population of these parties is comprised of a larger fraction of the group most likely to cause harm than is the original population of all parties engaged in the risky activity.) On the other hand, there is no such favorable tendency under regulation, all the parties being equally subject to verification procedures in the absence of special information about their category of risk. 
Summary. The discussion to this point may be summarized as follows: that (i) to the extent private parties possess information about risky activities which is superior to a regulatory authority's, the desirability of allowing the parties to decide how to reduce risk will be enhanced, and thus, so will be the appeal of the liability approach over the regulatory; that (ii) the problem of inability to pay for the full magnitude of harm done reduces the deterrent inherent in liability and is therefore an argument in favor of regulation; that (iii) the likelihood that suit would not be brought is for similar reasons a factor that works in favor of regulation; that (iv) consideration of administrative costs may favor liability because under it and not under regulation, such costs are borne only if harm actually occurs; but this argument was qualified in several ways.

Joint use of liability and of regulation. To conclude this section, it should be observed that the determinants favoring liability and those favoring regulation ought both generally to have enough importance to make desirable some degree of use of each means of controlling risk. Consideration of the four determinants is therefore to be regarded as determining the best balance between liability and regulation, not which approach ought to be employed to the exclusion of the other.

If, then, some measure of jointness of use of liability and regulation is likely to be advantageous, what can be 
said about the two questions that are immediately raised concerning the relationship between satisfaction of regulation and liability? That is, should a party's adherence to regulation relieve him of liability? And on the other hand, should a party's failure to satisfy regulatory requirements result necessarily in his liability?

Theory suggests that the answer to both these questions ought to be in the negative. In respect to the first, if satisfaction of regulatory requirements were to render parties immune from liability, then none would do more than to satisfy the requirements. But there will generally be parties who ought to do more to reduce risk than what is called for by regulation because they bear lower than usual costs of taking care or present a higher than usual potential for doing harm, or because there are aspects of their behavior which affect risk but are not covered by regulation (due to limitations of knowledge on the part of the regulatory authority). And since some among these parties would be induced by liability to take more care to reduce risk (for some would be able to pay for harm done and would be sued with sufficiently high likelihood), it becomes desirable to employ liability as an additional means of controlling risk. ${ }^{16}$

At the same time, if failure to satisfy regulation were necessarily to result in a party's liability for negligence, then some parties would be inappropriately led to satisfy regulation who would not otherwise have done so. This is 
because some parties for whom the regulatory requirements would not be desirable--those facing higher than usual costs of care or posing less than the usual potential for harm--will not have been forced to satisfy the requirements due to flaws in or probabilistic methods of regulatory enforcement. Yet these parties might still be induced by threat of liability to obey the requirements. But allowing recognition in liability law of the parties' special circumstances will lead, desirably, to their not adhering to the regulatory requirements after all. 17 
II . Activities Controlled Mainly by Liability; the Typical Tort.

It will be suggested now that there exists a rough consistency between the theoretically desirable use of liability and of regulation and their use in fact. In arguing thus, attention will be focused in this part on activities which are controlled mainly by liability; and for concreteness, reference will often be made to the two activities mentioned earlier--to my chopping down the tree that might fall on a neighbor's garage; or to my running to catch a bus and possibly colliding with someone in so doing. It will be seen by examining in turn the four determinants that such activities as these ought to be controlled primarily by liability, that the drawbacks of regulation would probably be acute.

Consider first the determinant concerning the possession of information about risk. When one thinks about this matter in some detail, one comes to believe that private parties would, as suggested above, know more, and much more, than a regulatory authority. I would likely know significantly more than an authority about the danger involved in felling a tree in my backyard and the costs of reducing the danger because I would know the position of this particular tree relative to my neighbor's particular garage; how difficult it would be to lower risk by use of guy wires; or how time consuming it would be to cut down the tree in stages. 
Similarly, I would know more than an authority about the chance of knocking someone down when running for a bus at this particular speed at that particular corner; and how hard it would be to take greater care in running for the bus and the consequences of failing to catch it.

The reason why $I$, or, private parties will usually have much more information than a regulatory authority about the risks associated with tortious activities and the cost of reducing them is evidently that this information will truly be a byproduct of engaging in the activities and because the conditions determining the nature of risks will be so various and subject to changing circumstance.

As a consequence of the superiority of private parties' information, it seems that reasonably satisfactory decisions should be made under liability, whereas costly mistakes would be unavoidable under regulation. Were a regulatory authority to set forth rules concerning the felling of trees in backyards and the proper pursuit of buses, it is a surety that the rules would sometimes be too restrictive. In instances where it would be safe to chop down my tree or to hurry after a bus, I might be required by regulation to take needless precautions--precautions which I would not take on account only of my potential liability. Conversely, it is plain that the authority's rules standing alone would sometimes be insufficiently demanding; I might find it very easy to take a precaution in chopping down a tree that was not required by regulation; only because of a concern for liability 
would I be led to take the precaution. It does thus appear that behavior under regulation often would be much inferior to that resulting from liability on account of a regulatory authority's relative lack of information.

Consider now the second determinant, that of ability to pay for harm done. Here, admittedly, there is a potential problem; there will frequently be some possibility that a party will not be able to pay for harm done. Nevertheless, this does not seem to be an issue of great significance in respect to many of the activities of present interest. If my tree falls and damages my neighbor's garage, it is reasonably likely that I will be able to pay what is necessary to repair it; if I own or rent a house, I should probably have assets plus liability insurance sufficient to cover damage to the garage. While inability to pay for harm done is conceded to be a factor reducing the deterrent of liability in respect to the typical tort, it does not stand out as a problem of unusual dimension (at least by comparison to many of the situations discussed in the following part of the article).

Next, consider the likelihood that suit would be brought for harm done. This likelihood appears to be relatively high for the typical tort, as none of the reasons given for failure to bring suit would usually seem to apply. In particular, the dispersal of harm over many victims is not a 
characteristic of the typical tort; when my tree falls, it might damage the property of one, not many neighbors; when I run for a bus, I am unlikely to collide with more than one or two individuals. Similarly, the passage of a long period of time between an injurer's action and the occurrence of harm is not a feature of the typical tort; rather the harm that I might do in chopping down my tree or running for a bus will be direct and immediate; for the usual tort, the injurer's action will be quickly followed by harmful consequences if there are to be any. The other possible cause of failure to bring suit was the chance that harm would not be attributable to a responsible party, and, again, there does not seem to be any special difficulty in respect to the usual tort; if my tree falls on my neighbor's garage, he will know what did the harm. In sum, then, none of the reasons for failure to bring suit should usually be of significance in situations presenting the risk of the typical tort and, hence, do not constitute an argument for regulation.

Regarding, finally, the determinant of administrative costs, consider the interpretation of what was said in Part II. The initial point was that liability should have an underlying cost advantage because we would expect it to be less expensive for society to bear administrative costs only in the event of harm than independent of the occurrence of harm. The relevance of this point does seem to be confirmed by our examples; one does have the impression that it 
would be significantly less costly for society to incur administrative costs only when falling trees happen to descend on garage roofs or only when individuals running for buses happen to collide with others--fairly unlikely events-than for society to formulate and enforce regulations concerning whether trees are chopped down and how so, and whether individuals may walk only at a normal pace to catch a bus or may be allowed to hurry after it. ${ }^{18}$ Indeed, when one stops to think about it, virtually all our entirely routine activities (walking, mowing a lawn, playing catch) are seen to be, like the examples, perfectly innocuous in the overwhelming majority of instances. Thus the savings over regulation that are realized under liability on account of the limitation of administrative costs to those numerically few occasions when harm is done must be great.

(The notion of effective regulation of the activities of everyday life even seems fanciful to contemplate. Perhaps this is because it would be made particularly difficult by the necessity of frequent and likely intrusive verification procedures; for what would usually need to be determined by a regulatory authority are aspects of readily modifiable individual behavior rather than the presence of "fixed" physical objects. $)^{19}$

Last, the earlier noted tendency for administrative costs to be concentrated under liability on those most likely to cause harm can also be seen to be of relevance; it makes sense to believe there will be a much higher propor- 
tion of awkward individuals among the group who succeed in knocking down others when running for buses than among the group of all those who chase after buses; and it would be a waste to monitor the behavior of the many relatively agile individuals in the latter group who do not cause accidents, but that is what would be done under the regulatory approach.

Let us now summarize our review of the determinants. We first argued that a reasonably strong case exists in favor of liability due to the likely superiority of knowledge of private parties over a regulatory authority's; and we just argued that a strong case for liability results from consideration of savings in administrative costs; we thought that only a moderate advantage of regulation exists in connection with parties' inability to pay for harm done; and we saw no real reason to believe that there would be systematic failure of victims to bring suit and thus no advantage of regulation arising in that regard. Taking these four arguments into account--the two working strongly in favor of liability, the one working with only some force against it, and the other of little relevance--the conclusion is that liability ought to be employed and that regulation ought not to be much used in controlling the risk of the typical tort. The theoretically desirable solution to the control of this familiar category of risk is thus seen as consistent with the solution observed in practice. 
IV. Activities Controlled in Significant Ways by Regulation

It will be the aim here to demonstrate by examining again the four determinants that it is desirable that society resort to safety regulation where it does--in controlling the risks of fire, the production and sale of many foods and drugs, the generation of pollutants, and the transport and use of explosives and other dangerous materials. The claim, in other words, will be that regulation in these areas is no coincidence but rather is needed because liability alone would not result in adequate reduction of risks and because the usual disadvantages of regulation are not so serious, or at least are outweighed by its advantages.

Consider first the determinant concerning information about risk. Here it appears that what typifies much regulation is that its requirements can fairly reliably be justified by common knowledge or something close to it. Presumably, most of us would agree that it is well worthwhile for explosives to be transported over routes that avoid the drastic risk of explosions in tunnels; that expenditures on highly strong elevator cables are warranted by the resulting reduction in the probability of fatal accidents; that expenditures on pasteurization of milk are made desirable by the decreased chances of bacterial contamination. In such examples as these, it seems that the regulatory authority can be reasonably confident that its requirements are justified in the great majority of situations. This is not to 
say, of course, that they will be justified in all situations. There will obviously be some occasions when milk will be consumed soon enough that failure to pasteurize it would lead to no real risk. But these occasions will be few in number, and the error due to inappropriate regulation will accordingly be small.

In addition, even where this argument does not apply-because the design of appropriate regulation requires much more than common knowledge--it may still be true that the regulatory authority enjoys an informational advantage. This situation perhaps obtains in respect to certain healthrelated and environmental risks for which expert medical, epidemiological, or ecological knowledge is needed for proper assessment. small firms using toxic substances, for instance, could well be thought to know little about and to have a limited capacity to understand the risks they create, and the same might sometimes be true of large firms. The reason that this possibility arises is that it may be uneconomic for firms individually to develop and maintain expert knowledge about toxic substances; there may be economies of scale involved in the acquisition of knowledge about the substances and external benefits associated with it making a regulatory authority or a governmental agency the more logical entity for the purpose of securing the knowledge. 20 (Nevertheless, it is hardly claimed that this will usually be the case in areas where substantially more than common knowledge is needed to determine regulatory requirements.) 
Let us now consider the second of the four determinants, ability to pay for harm done. This determinant seems to be of general value in explaining why we regulate the activities that we do, for these activities frequently create risks which can readily be imagined to exceed the assets of responsible parties. Injury due to fire at a nightclub or hotel, for example, could clearly result in larger losses than the assets of its owner; the harm caused by mass consumption of spoiled food or by inoculation with vaccines with adverse side-effects could easily surpass the assets of a packager of food or a drug company; the losses caused by explosions, oil spills, chemical pollutants, radioactive or other carcinogenic substances could with not insubstantial probability exceed the assets of even the largest corporations. It is thus apparent that in many areas of regulation, potential liability could well be larger than the assets of an involved firm (certainly of the personal assets of any of its employees) and therefore that the deterrent effect of liability alone would not result in adequate reduction of risk.

Consider next the determinant concerning the likelihood of being sued for harm done. As a brief reconsideration of the factors that lead to failure to bring suit will demonstrate, this determinant seems to be of significance in explaining the regulation of a wide class of environmental and health-related risks. First, many environmental and 
health-related risks evidently are sufficiently dispersed that it is not worth victims' while to bring suit on an individual basis. Second, many such risks often take a long time to eventuate. This is both because harmful agents may not produce adverse effects until years after their introduction into host bodies and because the agents may retain their potency for extended periods. As a consequence, and as remarked generally earlier, by the time harm occurs the evidence necessary to bring a successful action may be hard to develop, responsible individuals may have separated from their firms or have died, and firms themselves may have gone out of business. Third and last, environmental and healthrelated risks frequently have the characteristic that when they occur, it is difficult to attribute them to a particular firm or to a particular cause. This in turn is true for a variety of reasons: as just mentioned, the time that it takes for risks to eventuate; the often complex and incompletely understood nature of the risks; and the fact that the risks are sometimes truly due to more than one cause. Thus, it indeed seems to be the case that environmental and health-related risks often do not result in an appropriately high potential liability burden to the firms that caused them; and that even where this is not so, the responsible individuals within the firms may not face an appropriate chance of incurring liability or of bearing a sanction internal to the firm. In either event, therefore, the rationality of use of regulation is suggested. 
Consider, finally, the determinant of administrative costs. As explained before, there may be an underlying cost advantage in favor of liability, but two qualifying factors were mentioned. One was the cost per instance of verifying adherence to regulation. And this, we indicated earlier, should typically be lower when regulation requires the presence of particular things (fire extinguishers, guard rails, life boats) than when it requires adoption of particular modes of behavior, and much regulation requires the former. Moreover, even when regulation concerns modes of behavior, the cost of verifying adherence may relatively be low if there is little chance of concealment of the behavior. How easy would it be, for instance, for a dairy to keep secret its failure to pasteurize milk given the ease with which a sample could be tested, the large number of employees who would be aware of the firm's practices, and so forth? The other qualifying factor noted was the possibility of reducing monitoring costs by use of probabilistic methods of enforcement. In this regard, it need only be said that such methods of determining compliance with regulations are often employed. Thus, the administrative costs of verification of adherence to regulation per instance appear sometimes actually to be low; while if not, at least some savings are realized by use of probabilistic means of enforcement.

At this point, having discussed the four determinants in relation to activities that are regulated in significant 
ways, the claim of consistency with theory should seem plausible. For most such activities, the two affirmative arguments for regulation--the problem of inability to pay for harm done, and the possibility of failure to bring suit--should seem to outweigh the two potential disadvantages of regulation--the lack of information of the regulator and the size of administrative costs. (It is clear from what we have said, however, that the relative importance of the different arguments may vary according to the activity; thus our statement must be carefully interpreted. ${ }^{21}$ )

The general claim of consistency of the theory with the choice society has made over which activities to regulate is given further support by consideration of the "second-order" choices society has made over which aspects of a regulated activity to subject to regulation and which not. While to reduce the risks due to fire there may be requirements concerning the display of exit signs or the installation of smoke alarms and sprinkler systems, there will inevitably be many routine practices that affect the risk of fire and which will not be regulated (e.g., whether to store flammable furniture polish in a closet through which a heating pipe passes). These unregulated aspects of risk appear usually to have the feature that it would involve great expense for the regulatory authority to enforce its standard (ensure that polish is kept out of the closet), or that the appropriate standard would be hard for the authority to determine 
because of the highly contextual nature of the information that would be needed (type of polish, surface temperature of heating pipe). In other words, the two advantages of liability--savings in administrative costs, and allowing parties to make decisions based on their superior information--seem to help explain what aspects of a regulated activity are left unregulated.

Finally, the claim of consistency of the theory with what is true in fact is confirmed also by the agreement between the theoretically desirable and the observed relationship between satisfaction of regulation and imposition of liability. Specifically, it is indeed the case that adherence to regulation does not necessarily relieve a party of liability. 22 Moreover, when liability is found despite adherence to regulation, the reason given is frequently phrased in terms of there being "unusual circumstances" or "increased danger," which is what we said theory suggests ought to give rise to liability despite satisfaction of regulation. 23 on the other hand, it is also true that failure to satisfy regulatory requirements does not automatically result in liability. 24 And the explanation that is often furnished in this regard, that a party's "violation of the [statutory] law" does not imply his negligence if the "circumstances" justify an apparent disobedience, again comports with theory. 25 


\section{v. Concluding Comments}

(a) While it was the claim in the

last two parts that the theoretical determinants discussed initially serve to explain the observed use of regulation of safety and of liability, it was stated several times that this is believed to be true only in an approximate sense. It is hardly thought that the use of the two means of controlling risk, when inspected in a detailed way, will uniformly seem rational in light of the theory presented here (or of any other simple theory).

Indeed, one not infrequently encounters the view that mistakes have been made in the use of regulation and liability. On the one hand, one sometimes hears it said that regulation is inadequate. Consider for example the claim that there has been insufficient control over the disposal of toxic wastes. This claim might well have merit: For at least until recently, the disposal of toxic wastes was little regulated, while the threat of liability probably provided an insufficient deterrent against improper disposal -- due to manifold problems of establishing causation and of the possibility that the harm done would exceed the assets of responsible parties. 26 on the other hand, one of course hears it asserted that certain regulation is unduly constraining. It is commonly argued, for instance, that various O.S.H.A. requirements and antipollution standards are too standardized or impose excessive costs on industry. 27 
That there should be examples of apparent social irrationality is really to be expected, for the choices actually made concerning regulation are obviously influenced by a multitude of factors lying outside our framework of analysis (notably, the pressures of interest groups ${ }^{27 a}$ ), and, in any event, often will not reflect conscious, careful use of a social cost-benefit calculus. Moreover, the complexity of the relationship between liability and regulation, the possibilities for modification of the liability system as an alternative to use of regulation, and the many unanswered empirical questions supply further reasons to expect errors (relative to an ideal) to have been made.

(b) The theoretical determinants used here to analyze the choice between regulation and liability would be of relevance as well to a more complete assessment of the relative social desirability of alternative methods for controlling risk, and in particular, to one considering the use of fines for harm done ${ }^{28}$ and of injunctions. It therefore seems worthwhile indicating what would probably be the major points of such an assessment.

Consider first the use of a fine. This method of controlling behavior is identical to liability in the respect that it creates an incentive toward reduction of risk which works through parties paying for the harm they turn out to do. Thus, the fine enjoys essentially the same advantages as liability -- the private parties balance the costs of 
reducing risks against the benefits; and society bears administrative costs only when harm is done. Also, the fine suffers from similar disadvantages -- inability to pay for harm would dilute the effect of its use, as would the possibility that the fine would not be levied.

But the fine differs from liability in that it is public in nature; a private party does not institute the fine and does not benefit financially when it is collected, a public agency does. The principal implication of this difference is perhaps that the likelihood of collection of the fine may differ from the likelihood a party would be sued. In most contexts, one supposes that this difference would work against the fine; as private parties would usually know better than a public agency when harm occurred and might profit from bringing or threatening suit but not from informing a public agency of harm so that it could impose a fine, the likelihood of suit would be higher than that of a fine. 29 Nevertheless, there are circumstances in which the advantage would lie in the other direction: where a suit would not be brought because of difficulty in establishing causation under the usual tort principles, the fine could still be imposed; and similarly where private parties are unaware of the harm or it is too dispersed to make legal action worthwhile. ${ }^{30}$ Finally, another difference between the fine and liability is in the size of administrative costs. This difference, one speculates, might work against liability as a general matter, assuming that its use is procedurally more complex than that of the fine. 
With regard now to the injunction, observe that it resembles regulation of safety in that it works in a direct way to control risk; the injunction prevents harm simply by proscribing certain behavior. Hence, the injunction shares advantages similar to those of safety regulation: the use of the injunction is in no way impeded by the possibility that a party would not be able to pay for the harm he does, 31 or by the chance that the harm would be highly dispersed or difficult to attribute to him under tort principles. 32

The injunction differs from safety regulation, however, in that it is employed at the urging of private parties. This would seem to offer an advantage over safety regulation where the private parties have better information about the nature of potential harm. Still, the fact that the injunction is brought by private parties would amount to a disadvantage where they would not have superior information about potential harm, or where, because the harm would be of a general nature and spread over many parties, they would not find it individually worthwhile to take legal action and would face difficulties in coordinating a collective action. 


\section{Footnotes}

* Professor of Law and Economics, Harvard Law School. I wish to thank S. Rose-Ackerman, L. Bebchuk, P. Burrows, L. Kaplow, M. Kelman, R. Stewart, and, especially, R. Epstein for comments and the National science Foundation (grant no. SES -8014208) for financial support. A formal version of the main argument of this article is made in my Harm as a Prerequisite for Liability, Harvard University, 1979, and in A Model of the Socially Optimal Use of Liability and Regulation, Harvard Law School, 1983. The present article will provide the basis for a chapter in the part on torts of a book $\underline{A}$ Theoretical Analysis of Law on which I am at work.

1. Of course, liability and regulation might be viewed as serving purposes distinct from the control of risk; notably, liability might be seen as a means of compensating those who have suffered harm, and regulation as reflecting in part the influence of interest groups. In the interest of clarity, however, this article will abstract from functions of liability and regulation other than the control of risk. (But see note 3 , infra.)

1a. As the chief goal here is to compare liability and regulation, there will be no explicit attempt to identify the extent to which the conclusions reached may be separately attributed to the first dimension in which 
the approaches differ (employed only after harm is done vs. before) or to the second dimension (employed at the initiative of private parties vs. of a public agency). Neither will there be an attempt to discuss other approaches to controlling risk, except, as will be indicated, in the concluding comments.

2. This is hardly to deny that I would try to avoid colliding with someone for reasons independent of the fear of legal sanctions, but, again for expositional convenience, in analyzing parties' behavior here, attention will be limited to the legal consequences of acts.

2a. This is the general approach adopted by two influential legal scholars in their analysis of the problem of accidents; see Guido Calabresi, The Costs of Accidents, 1970, and Richard Posner, Economic Analysis of Law, (2nd ed.) 1977, Chapter 6.

3. The reason that the compensatory objective is excluded is not that it is thought unimportant but rather that the objective does not appear to bear significantly on the subject of the article. The latter seems the case because under either the liability approach or the regulatory, potential victims have the opportunity to purchase first-party insurance coverage; and if it is felt that this would not provide them adequate coverage (perhaps because they would fail to make rational purchase of insurance or because they would not be able to afford it), the state could always establish a public insurance program. 
4. See John P. Brown, Toward an Economic Theory of Liability, $2 \mathrm{~J}$. Legal studies 323 (1973).

5. Consideration of the possibility of changes in the risks or the costs of their reduction suggests that a private party should have an advantage in knowledge even if the regulatory authority were assumed able to assess perfectly accurately his situation at the time it observed him. Only if the regulatory authority were presumed to monitor continuously the party's situation would it possess knowledge equal to the party's.

6. In part, this is because the facts presented to the courts will often reflect changes in parties' situations; see note 5 , supra.

7. The regulatory authority might possess the superior information for well known reasons: First, the authority (or some governmental agency) might have decided to commit resources to the acquisition of information about risk in light of a socially inadequate incentive of private parties to do so. The incentive of private parties might be inadequate because of their inability to appropriate the full social benefits of information that they develop; others will often learn what they have discovered and benefit from it without paying them; see generally Kenneth J. Arrow, Essays in the Theory of Risk Bearing, 1971, Chapter 6 .

And second, the regulatory authority might be better suited to acquire information about risk because 
it requires assembling relatively large groups of experts; it would be wasteful and unnecessary for such groups to be assembled by multiple private parties.

8. See more generally, Steven Shavell, The Judgment Proof Problem, Harvard Law School, 1984.

9. In saying this, we are ignoring the possibility that in some contexts enforcement of a regulation could itself become a problem due to parties' low assets.

10. Consider whether a party with assets of $\$ 20,000$ and facing a potential liability of $\$ 100,000$ would wish to buy liability insurance coverage. For the party to purchase coverage would be for him to purchase protection against $\$ 80,000$ of risk which he would not otherwise bear. This means that his premium for coverage would be much higher--five times so--than what would be the premium for the risk of his $\$ 20,000$ of assets alone. Hence, the party might well rationally decide against purchase of coverage (even though he would have purchased coverage if his assets had been as large as $\$ 100,000)$. See William Keeton and Evan Kwerel, Externalities in Automobile Insurance and the Underinsured Driver Problem, Yale University, 1983; and Shavell, note 8 , supra.

11. To illustrate this possibility, consider the party of the previous note, suppose that liability insurers cannot observe anything about his efforts to reduce risk, and suppose too that he is legally obligated to 
purchase full coverage of $\$ 100,000$. Then, being fully covered (and the premium or policy terms not being dependent on his behavior), the party will have no motive whatever to reduce risk. But if he had not been obligated to buy the coverage and would have decided against doing so (as explained in the previous note), he would have had some incentive to reduce risk, for at least his assets of $\$ 20,000$ would then have been at stake. See Shavell, note 8 , supra.

12. As it stands, what we have argued is really only that some form of ex ante control of a firm's decisionmakers may be socially desirable. But the firm itself might be expected to employ ex ante controls to reduce its corporate liability where ex post sanctions would be unsatisfactory. (If a firm's potential liability is $\$ 1,000,000$ and the relevant decisionmaker's assets are only $\$ 50,000$, then the firm would wish to control directly his behavior to lower the risk of incurring the $\$ 1,000,000$ in liability; as the decisionmaker's potential loss is far lower, the firm would not wish to rely solely on the prospect of an ex post sanction to induce the decisionmaker to act so as to avoid corporate liability). Thus, to complete our argument that the limited assets of firms' decisionmakers may constitute an argument in favor of regulation, we must demonstrate that regulation would often be expected to be superior to ex ante controls imposed by the firm. 
To this end, consider first "managerial" decisionmakers, by which we mean individuals whose activities are overseen only by the board of directors and the shareholders--and thus not by superiors within the firm. Now the board of directors and the shareholders would not be likely to know as much as a regulatory authority about the nature of risks facing the firm, for it is implausible that they would have the time or the necessary expertise to devote to this matter. Thus the suspicion is that the regulatory authority would enjoy an informational advantage in controlling the behavior of managerial decisionmakers.

However, in regard to "line" decisionmakers, those whose activities are overseen by superiors within the firm, this argument becomes problematic; for the natural presumption would be that the superiors within the firm would have better information than a regulatory authority about the nature of the risks confronted by the line decisionmakers. Nevertheless, that will not always be true, and it will sometimes be cheaper and more practical for a regulatory authority to enforce controls than for management to do this. (A harbor authority would be likely to know more about the risks at its port than would the management of a shipping company, and, further, be able to regulate docking procedures of the company's ships more cheaply than management due to economies of scale.) In addition, 
and perhaps more important, the incentive of management to regulate the behavior of line decisionmakers may be inadequate due to the very problem that a managerial decisionmaker's potential liability might be less than the firm's. Hence, it seems plausible that a regulatory authority would sometimes be expected to control in a more desirable way line decisionmakers than would the firm itself.

For a general discussion of closely related issues, see Christopher stone, The Place of Enterprise Liability in the Control of Corporate Conduct, 90 Yale L. J. 1 (1980); and see also Lewis Kornhauser, An Economic Analysis of the Choice Between Enterprise and Personal Liability for Accidents, 70 Calif. L.R. 1345 (1982).

13. Discussion of modifications of the tort system which would alleviate this problem of attribution--notably, imposing liability in proportion to the probability of causation--are beyond the scope of this article. On this matter, see Comment, DES and a Proposed Theory of Enterprise Liability, 46 Fordham L. Rev. 963 (1978); M. David Rosenberg, The Causal Connection in Mass Exposure Cases, forthcoming Harvard L. Rev.; Steven Shavell, Uncertainty over Causation and the Determination of Civil Liability, Harvard Law School, 1983.

14. The administrative costs associated with use of the liability system include parties' litigation costs and other legal expenses, and also the public costs of 
conducting trials, employing judges, and so forth. similarly, the administrative costs associated with regulation include parties' costs in proving their compliance with regulatory requirements (e.g., time spent completing forms and undergoing inspection by regulatory officials) and the operating cost of the regulatory authority.

14a. That is, the victim either will not threaten legal action--for lack of a case--or he will do so and will settle with the other party. Thus, the administrative costs per accident will frequently, if not usually, be substantially less than those associated with actual litigation.

14b. See Donald Wittman, Prior Regulation versus Past Liability: The Choice Between Input and Output Monitoring, 6 Journal of Legal studies 193 (1977), for an analysis of optimal probabilistic enforcement in a setting similar to that of this article.

15. Specifically, the minimum frequency of verification that will induce adherence to regulation exists because, among other things, there is a definite limit to the fine that can be imposed for failure to adhere -namely, the size of the party's assets. And the administrative costs using even this minimum probability of verification could easily exceed the administrative costs associated with liability, for accidents could occur with arbitrarily small or even with zero proba- 
bility. To illustrate, suppose that the assets of a party are $\$ 10,000$; that the costs of taking optimal care are $\$ 500$; that regulation calls for spending this amount; and that spending this amount would entirely - eliminate the possibility of accidents. Then the minimum probability of verification would be $5 \%$ (for the maximum effective fine of $\$ 10,000$ times the probability of verification must exceed $\$ 500$ to induce the party to adhere to regulation and to spend the $\$ 500$ ). Hence, the administrative costs of regulation would be positive. But since under liability the party would generally be led to spend the $\$ 500$ and accidents would therefore not occur, there would be no administrative costs whatever.

16. To illustrate this point, consider a situation where it is desirable that most parties, "typical" parties, spend $\$ 500$ on care because this will reduce expected accident losses by $\$ 1,000$; where a small fraction of "atypical" parties have the opportunity to reduce accident losses by an additional $\$ 1,000$ by spending $\$ 500$ more; where such atypical parties cannot be identified ex ante by the regulatory authority; and where some fraction of both types of parties have very limited assets, so that they would not be induced by potential liability to take care.

In this situation note that the regulatory standard would of necessity be the same for the typical and the 
atypical parties, owing to the assumed lack of information of the regulatory authority as to a party's true opportunity to reduce risk. Observe also that the best such regulatory standard of care would correspond to the $\$ 500$ expenditure, for an expenditure of $\$ 1,000$ would be appropriate only for the small minority of atypical parties.

Now if parties were never liable so long as they adhered to the regulatory requirement that they spend $\$ 500$ on care, then the atypical parties would never spend $\$ 1,000$, an undesirable outcome. But if there were a possibility of their liability despite satisfaction of the regulatory requirement, then the atypical parties with normal assets would, desirably, be led to spend the additional $\mathbf{\$ 5 0 0}$ on care. Thus liability would serve as a socially beneficial adjunct to regulation.

(Notice also that use of liability alone would be inferior to the described joint use of regulation and liability; for use of liability alone would result in the parties with limited assets (typical or not) taking no care rather than spending $\$ 500$. )

17. To illustrate this point, consider the situation described in note 16, supra, but with the following changes: the atypical parties are now distinguished by the characteristic that they would not lower the risk of an accident at all even by spending the first $\$ 500$ on care, so 
their making expenditures on care would be undesirable; and some fraction of all parties escape the attention of the regulatory authority.

In this situation, the regulatory standard would again have to be the same for both types of parties due to the regulatory authority's inability to tell them apart, and the best standard would again correspond to an expenditure of $\$ 500$ on care, as the atypical parties are assumed to be so few in number.

Now consider the question whether under the negligence rule an atypical party ought to be found negligent if he failed to satisfy the regulatory requirement that he spend $\$ 500$ on care. This question is relevant of course because an atypical party might not have been forced to spend $\$ 500$ as he might have escaped the attention of the regulatory authority. clearly, if such an atypical party would face no risk of liability for negligence if he did not spend the $\$ 500$, then he would not do so, the desirable result. On the other hand, if he did face the risk of liability for negligence if he failed to spend the $\$ 500$, then he might be led to do so, an undesirable result. Hence, it is best for the standard of due care to be relaxed and for atypical parties to escape liability for negligence despite their failure to adhere to the regulatory standard of care. 
It should perhaps also be stated that this example illustrates why there is no conundrum represented by the social "demand" for a certain type of behavior through announcement of regulatory requirements and yet the social "acceptance" of different behavior in the courts' sometimes not finding parties negligent for failing to comply with the requirements. The social rationality of this seeming contradiction lies in an appreciation of the significance of lack of information for the formulation of optimal regulatory requirements-the significance being that the requirements should not be viewed as an unconditional demand but rather as a demand which, while generally good, ought to be relaxed if the circumstances warrant it.

18. Suppose that the likelihood of the three which I cut down striking my neighbor's garage roof is .1\%; that the probability of a dispute over my negligence should this happen is $50 \%$; that the chance of such a dispute being settled is $75 \%$; that the administrative cost of a settlement would be \$100; that the chance of a dispute leading to a trial is $25 \%$; and that the administrative cost of a trial would be $\$ 1,000$. Then the likelihood of a dispute ending in settlement would be $.0375 \%$ and that of one resulting in litigation would be $.0125 \%$; hence the expected adminisrative cost associated with my chopping down the tree would be only .0375\%x\$100+ $.0125 \% \times \$ 1,000=\$ .0375+\$ .125=\$ .1625$. It is hard to 
imagine that a regulatory authority could, ex ante, determine compliance with its safety requirements concerning the felling of my tree for a comparably low amount.

19. To enforce effectively a regulation concerning an aspect of behavior which can be modified from one instance to the next ( I can run for the bus tomorrow even if I do not today) will generally require fairly frequent monitoring. By contrast, to ensure that a fixed physical object is in place (strong elevator cables are installed) will not require very frequent monitoring (the cables are not going to be replaced tomorrow).

20. The reader will recall that this point was made more generally in note 7, supra, but a brief discussion here of an example may be helpful. Consider the acquisition of information about the risks associated with use of a pesticide by firms engaged in the business of extermination. To determine the nature of these risks using even existing knowledge as incorporated in professional medical, public health and other related literature would require a staff of experts; a several-person exterminator firm could hardly be expected to undertake the required literature search, let alone be able to evaluate and interpret what is in the literature. And it is of course extremely unlikely that the firm would engage in research of its own. Moreover, to the argument 
that most exterminator firms might jointly and collectively finance efforts to evaluate current knowledge about the pesticide and to engage in further research, two answers can be given. First, it might be hard to make the firms contribute toward the common pool, for each might expect to benefit from the group's efforts regardless of its own contribution (the information about risk being difficult to restrict to those making contributions). Second, parties outside the group of exterminator firms (manufacturers of the pesticide, farmers who use the pesticide) might generally benefit from the information about the pesticide risk, meaning that the motive of the exterminator firms to acquire information about the pesticide might be less than society's (quite apart from the group's problems in making its members contribute to the pool).

21. With regard to health-related and environmental risks, for example, we argued that the likelihood that harm would not be attributed to responsible parties is an important consideration favoring use of regulation. But we made no such suggestion in regard to the risk of explosions in tunnels or the failure of elevator cables; we justified regulation of these risks on other grounds.

22. See William L. Prosser, Handbook of the Law of Torts, 4th ed., 1971, at 203.

23. See Prosser, note 22, supra, 204. Also, at 203, Prosser writes, "The statutory standard is no more than a 
minimum, and it does not necessarily preclude a finding that the actor was negligent in failing to take additional precautions. Thus the requirement of a hand signal on a left turn does not mean that. . a driver... is absolved from all obligation to slow down, keep a proper lookout, and proceed with reasonable care." This statement is in perfect agreement with our explanation from Part II, supra, where we said that the statutory standard ought to be regarded as a minimum since there would be parties who ought to take greater care and would not do so were they to escape liability on account of complying with the statutory standard.

24. See Prosser, note 22, supra, at 197.

25. See Prosser, note 22, supra, at 198. At 198 and 199, Prosser writes that "it has been held not to be negligence to violate . . a statute because of physical circumstances beyond the driver's control, as where his lights suddenly go out on the highway at night . . Another valid excuse is that of emergency, as where one drives on the left because the right is blocked, or a child dashes to the street . . ." such results obviously agree with what we said in Part II; that is, we do not want the driver to stay on the right side of the road when the child dashes out; holding him liable for being on the left would give him a socially undesirable incentive to drive on the right. 
26. See, for example, Note, "Allocating the Cost of Hazardous Waste Disposal," Harvard Law Review 94 (1981) 584 and references cited therein; Richard A. Epstein, "The Principles of Environmental Protection: The Case of the Superfund" Cato Journal 2 (1982) 9; and "Public Threat Feared in Loopholes in Laws on Toxic Waste Dumping," p.1, New York Times, June 6, 1983.

27. See, for example, stephen Breyer, Regulation and its Reform, Harvard University Press, 1982, Chapter 14; Albert Nichols and Richard Zeckhauser, Government Comes to the Workplace: An Assessment of O.S.H.A., The Public Interest 39 (1977); and for a general introduction to the issues, Ch. 5 of Richard stewart and James Krier, Environmental Law and Policy, Second Edition, Bobbs-Merrill, Indianapolis, 1978 .

27a. See for example George stigler, The Economic Theory of Regulation, 2 Bell J. Econ. 3 (1971), and Sam Peltzman, Toward a More General Theory of Regulation, $19 \mathrm{~J}$. of Law and Econ. 211 (1976).

28. The type of fine we have in mind is calculated to equal the harm done; from the perspective of the party who does harm, therefore, it is as if he is strictly liable.

29. If the tree falls on my neighbor's garage, it is more likely that he would sue to collect compensation but that he would report the incident so that I would have to pay a fine. 
30. Many environmental and health related harms of course provide cases in point.

31. This point is made in Robert Ellickson, Alternatives to Zoning: Covenants, Nuisance Rules, and Fines on Land Use Controls, 40 Univ. Chi. L. Rev. 681 (1973).

32. Thus, for example, just as regulation of the safety of nuclear reactors might be justified by the fact that incapacity to pay for possible harm would dilute the deterrent of liability, so could enjoining their operations in certain circumstances be justified. 